\title{
Electrochemical Behavior of n-tricalcium Phosphate and Graphene Oxide/Chitosan /n-tricalcium Phosphate Composite Coated Ti Metal, Ti-6Al-4V, and Co-Cr-W Alloys in Artificial Serum
}

\author{
Reham H. Tammam ${ }^{1, *}$, A. S. Mogoda ${ }^{1}$, H. H. Abo-almaged ${ }^{2}$, Sara G. Abd El-Kader ${ }^{1}$ \\ ${ }^{1}$ Chemistry Department, Faculty of Science, Cairo University, Giza 12613, Egypt \\ ${ }^{2}$ Refractories, Ceramic and Building Materials Department, Inorganic Chemical Industries and \\ Mineral Resources Division, National Research Centre (NRC), Cairo, 12622, Egypt \\ *E-mail: reham_tammam@cu.edu.eg
}

Received: 11 June 2021 / Accepted: 2 August 2021 / Published: 10 November 2021

\begin{abstract}
Nano-tricalcium phosphate (n-TCP) was prepared and its characterization was examined by X-ray diffraction, Transmission electron microscopy, and Scanning electron microscopy (SEM). The effects of coating of $\mathrm{Ti}$ metal, Ti-6Al-4V (TAV), and Co-Cr-W alloys with n-TCP or with graphene oxide/chitosan/n-tricalcium phosphate (GO/CS/n-TCP) composite on their corrosion in artificial serum were investigated by open circuit potential(OCP) and electrochemical impedance spectroscopy (EIS) techniques. The OCP of the uncoated, n-TCP coated, and GO/CS/n-TCP composite coated titanium metal, TAV, and Co-Cr-W alloys increase to a more positive value with time for about one hour before reaching a steady-state value in serum due to the growth of the air formed film on the surfaces of the materials. A two-time constants equivalent electrical circuit was used for fitting the experimental EIS results which were suitable for the passive film on the examined materials that consists of a barrier inner layer and a porous outer one. The impedance results revealed that the corrosion resistance increases with time and then decreases after 21 days as a result of the partial decomposition of the protective film on the surface of the electrodes. For all the studied materials here the corrosion resistance of their surfaces follows the order uncoated $<$ n-TCP coated $<$ GO/CS/n-TCP composite coated. Hence, coating of the tested material surface with n-TCP or composite assists the process of the passive film growth with time till a definite thickness but for a long time, this protective layer dissolves to a certain limit. SEM micrograph of the graphene oxide/chitosan/n-tricalcium phosphate composite coated Co-Cr-W alloy revealed that the composite contains very small pores which help the diffusion of ions through it causing the growth of the protective film on the alloy surface with time.
\end{abstract}

Keywords: Titanium; TAV; Co-Cr-W; n-TCP;EIS; SEM

FULL TEXT 
(C) 2021 The Authors. Published by ESG (www.electrochemsci.org). This article is an open access article distributed under the terms and conditions of the Creative Commons Attribution license (http://creativecommons.org/licenses/by/4.0/). 